\title{
Treatment of masseteric hypertrophy with botulinum toxin: A report of two cases
}

\author{
Burcu Baş ${ }^{1}$, Bora Özan ${ }^{2}$, Mehtap Muğlalı ${ }^{3}$, Nükhet Çelebi ${ }^{2}$
}

${ }^{1}$ Assistant Professor, Ondokuz Mayıs University, Faculty of Dentistry, Department of Oral and Maxillofacial Surgery, Turkey

${ }^{2}$ Research Assistant, Ondokuz Mayis University, Faculty of Dentistry, Department of Oral and Maxillofacial Surgery, Turkey

${ }^{3}$ Associate Professor, Ondokuz Mayıs University, Faculty of Dentistry, Department of Oral and Maxillofacial Surgery, Turkey

Correspondence:

Ondokuz Mayis University, Faculty of Dentistry

Department of Oral and Maxillofacial Surgery

55139, Kurupelit,

Samsun, Turkey

bora.ozan@hotmail.com

Received: 02/08/2009

Accepted: 24/12/2009

Baş B, Özan B, Muğlali M, Çelebi N. Treatment of masseteric hypertrophy with botulinum toxin: A report of two cases. Med Oral Patol Oral Cir Bucal. 2010 Jul 1;15 (4):e649-52.

http://www.medicinaoral.com/medoralfree01/v15i4/medoralv15i4p649.pdf

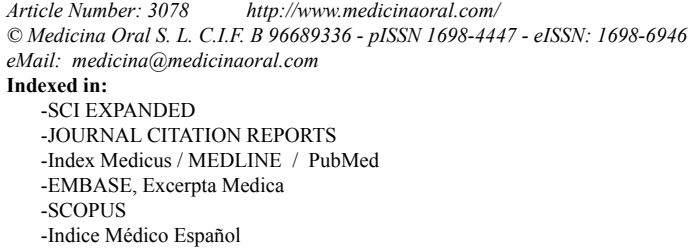

\begin{abstract}
Masseter muscle hypertrophy is a rare condition of unknown cause which is important in the differential diagnosis of head and neck masses, located in the cheek. Several treatment options reported for masseter hypertrophy, which range from simple pharmacotherapy to more invasive surgical reduction. Botulinum toxin type A is a powerful neurotoxin which is produced by the anaerobic organism Clostridium botulinum and when injected into a muscle causes interference with the neurotransmitter mechanism producing selective paralysis and subsequent atrophy of the muscle. Injection of botulinum toxin type A into the masseter muscle is generally considered a less invasive modality and has been advocated for cosmetic sculpting of the lower face. Botulinum toxin type A injection is considered to be a beneficial treatment modality in masseter muscle hypertrophy patients. The aim of this article is to report two cases of masseteric muscle hypertrophy which were treated with botulinum toxin type A injection. Marked changes in facial feature were achieved 3 months after the procedure.
\end{abstract}

Key words: Masseter muscle, hypertrophy, botulinum toxin type A.

\section{Introduction}

Masseteric hypertrophy ( $\mathrm{MH})$ is recognized as an asymptomatic enlargement of one or both masseter muscles (1). Although it is tempting to point to malocclusion, bruxism, clenching, or temporomandibular joint disorders, the etiology in the majority of cases is unclear (2). A congenital variety also exists, but acquired $\mathrm{MH}$ is by far most frequent (1). Most cases of $\mathrm{MH}$ are bilateral and symmetric, but asymmetry is not unusual. Unilateral occurrence also can be seen when patients chew or clench primarily on one side (1).
The traditional method of treatment for $\mathrm{MH}$ is the surgical partial excision of masseter muscle under general anesthesia. Complications from surgical excision of masseter include hematoma formation, facial nerve paralysis, infection, mouth opening limitation and sequelae from general anesthesia (3). Injection of botulinum toxin type A into the masseter muscle is first introduced by Smyth, and Moore and Wood in 1994 and considered a less invasive modality and for cosmetic sculpting of the lower face $(4,5)$. Botulinum toxin type A injection is reported to be a safe and effective treatment modality in 
orofacial dystonies, sialorrhea, frey's syndrome, muscle hypertrophies, etc (6-9).

Botulinum toxin type $\mathrm{A}$ is a powerful neurotoxin which is produced by the anaerobic organism Clostridium botulinum and when injected into a muscle causes interference with the neurotransmitter mechanism producing selective paralysis and subsequent atrophy of the muscle $(10,11)$.

The aim of this report is to present two cases of masseter muscle hipertrophy which were treated with botulinum toxin type A injection.

\section{Case Reports}

Case report 1

A 26 year-old woman with a swelling on her left masseteric region which existed for 2 years was refered to our clinic. The patient had no history of systemic diseases. Extraoral examination showed an obvious unilateral swelling centered over the mandibular angle (Fig. 1a). Palpation indicated that the swelling tissue was normal in tone and non-tender. When the patient was asked to clench, the swelling became more prominent and firm. Intraoral examination revealed a missing maxillary molar tooth at right side. The patient revealed that she uses the left side while chewing. Magnetic resonance imaging (MRI) showed no underlying pathology. Botulinum toxin A injection into the masseter muscle was planned for the patient.

Case report 2

A 28 year-old man with bilateral swelling of masseteric regions was refered to our clinic (Fig. 2a). He was in

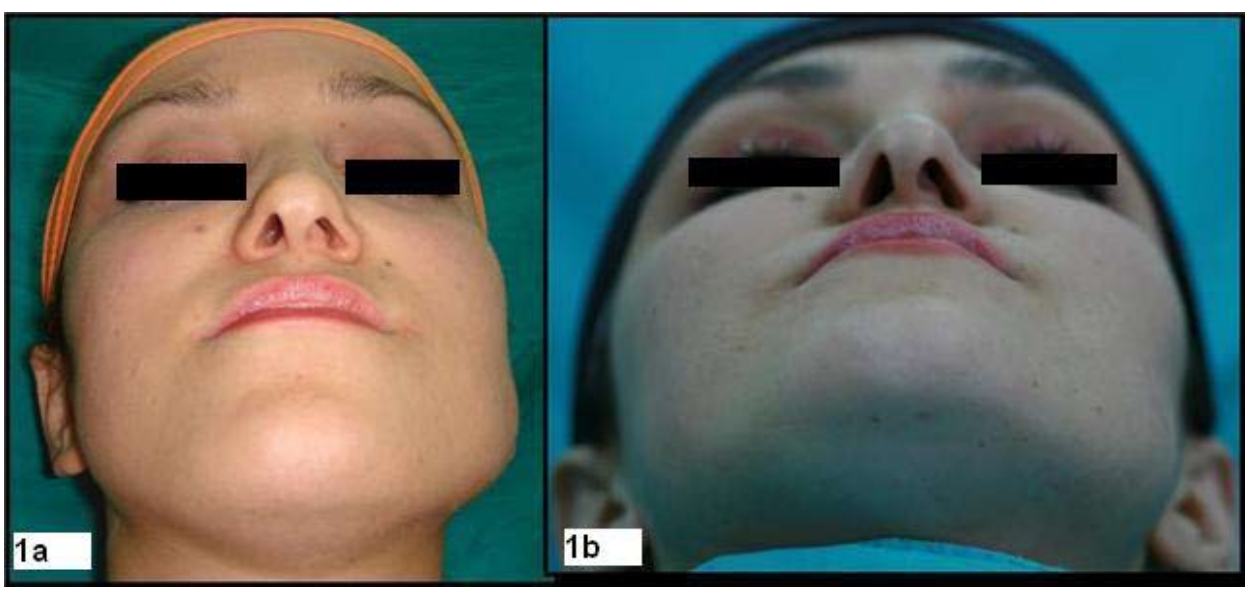

Fig. 1a. Extraoral view of the first patient before injection $\mathrm{b}$ : extraoral view of the patient, 3 months after injection.

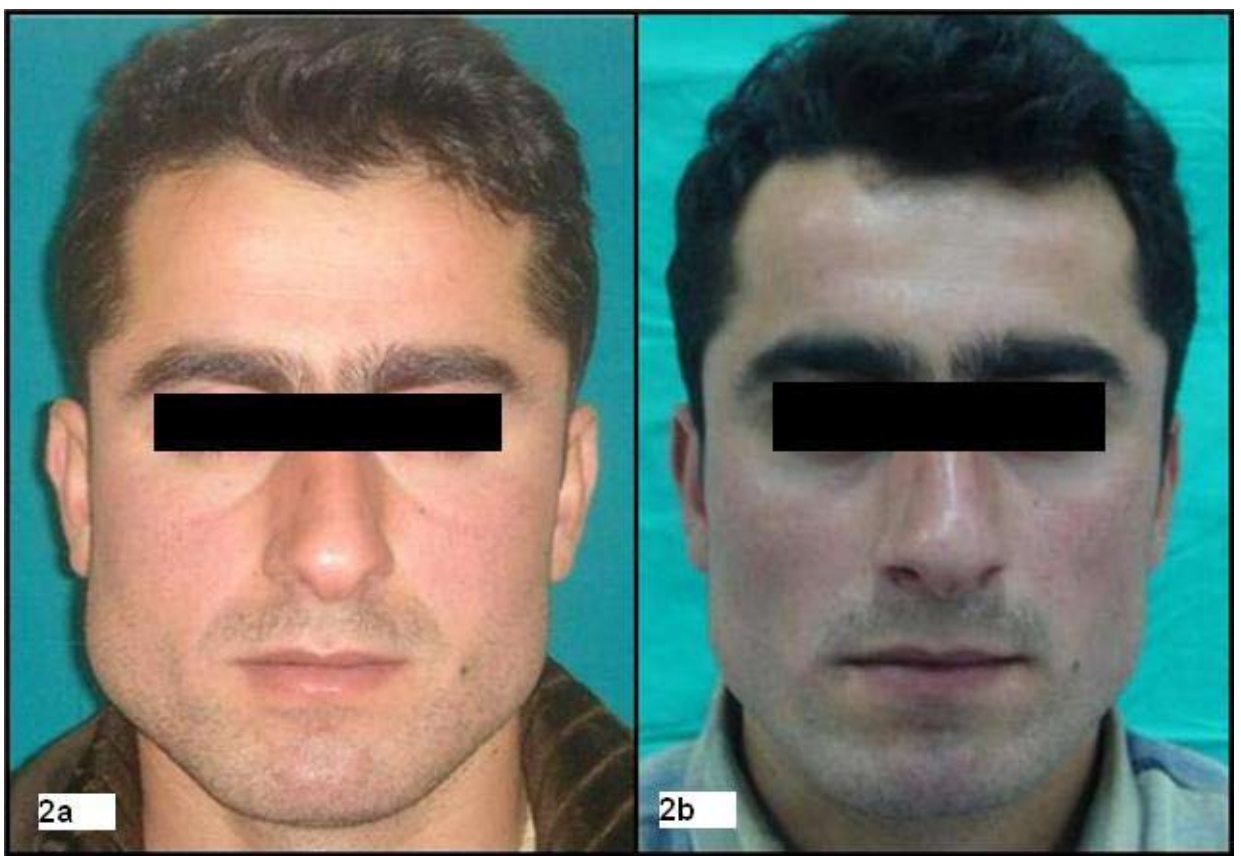

Fig. 2a. Extraoral view of the second patient before injection $\mathrm{b}$ : Extraoral view of the second patient, 3 months after injection. 
good health. Extraoral examination revealed bilateral hypertrophic masseter muscles. No abnormality was seen in intraoral examination and there was no potential etiologic factor in his history. MRI and Ultrasonographic imaging showed no underlying pathology.

\section{Injection Procedure}

Before the procedure the nature and the established use of botulinum toxin A as well as its potential side effects were explained and signed inform consent was obtained from each patient. Botulinum toxin A (BOTOX $\left.{ }^{\circledR}\right)$ was supplied a freeze-dried powder of 100 units and was reconstituted with $2 \mathrm{ml}$ of sterile saline solution, giving a concentration of 50 units $\mathrm{ml}-1$. In the first case, percutaneus intramuscular injection of the botulinum toxin $\mathrm{A}$ was performed to the hypertrophic muscle using $2 \mathrm{ml}$ syringe with $25 \mathrm{G}$ needle. 75 units botulinum toxin A was injected equally into three points at the center of the lower third of the masseter muscle which were located $1 \mathrm{~cm}$ from each other (Fig. 3). In the second case, percutaneus intramuscular injection of the botulinum toxin A was performed to the hypertrophic muscle bilaterally using $2 \mathrm{ml}$ syringe with $25 \mathrm{G}$ needle. 50 units botulinum toxin $\mathrm{A}$ was injected each side, equally into three points at the center of the lower third of the masseter muscle which were located $1 \mathrm{~cm}$ from each other.

Facial paralysis was seen in case 1 that improved in 2 weeks. There was no postoperative complication in case 2. The patients were seen for follow-up examination, and within 3 months satisfactory masseter muscle atrophy occurred in both patients (Fig. 1b,2b). Both patients are pleased with their present facial appearance.

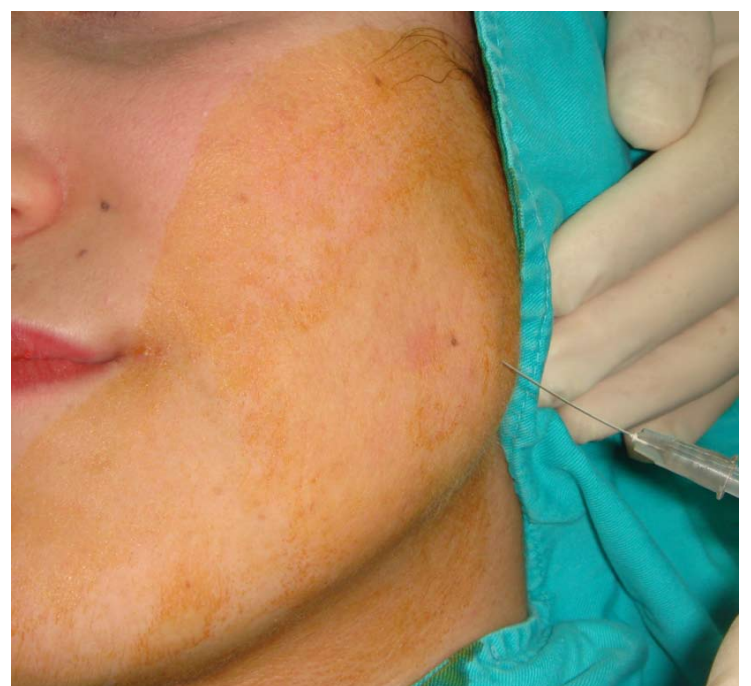

Fig. 3. Intramuscular injection of the botulinum toxin type A.

\section{Discussion}

The etiology of masseter muscle hypertrophy has been attributed to a number of factors such as emotional stress, chronic bruxism, masseteric hyper-function and para-function, and microtrauma (12-15). In our first case the etiologic factor was probably unilateral chewing habit of the patient due to her missing teeth. After the injection, prosthetic reconstruction was performed to cease the etiology and stabilize the outcome in this case. However, there was no history of any etiological factors in the second case.

Diagnosis of masseter hypertrophy cannot solely be based on clinical findings and there are conflicting recommendations in the literature for investigating patients presenting with benign bilateral masseter hypertrophy. It is important to make differential diagnosis of head and neck masses, particularly a unilateral mass located in the cheek (16). The possible underlying pathological factors should be assessed carefully with imaging techniques before the treatment.

The possible complications of this procedure are external scar and damage to the mandibular branch of the facial nerve, change in bite force, speech disturbance, muscle pain, facial asymmetry, and prominent zygoma $(17,18)$. In our first case temporary marginal mandibular nerve paralysis was occurred and improved in two weeks. Special attention should be focused on the risk of damaging the facial nerve during the injection. However, this can be an inevitable complication due to anatomic variations.

Perhaps the biggest limitation of botulinum toxin therapy is that the treatment effect wears away in 6 months and the original condition returns. Unlike surgical excision of muscle tissue that reduces the actual number of muscle cells, botulinum toxin type A only reduces muscle volume temporarily (3). Therefore, patients have to be informed about the recurrence rate after the procedure.

In this report, we presented the use of botulinum toxin A injection in the treatment of two patients with masseter hypertrophy. Satisfactory esthetic improvement was maintained in both cases. However, well-designed, adequately powered, randomised controlled clinical trials are needed for making a definate comment on the success of the this treatment.

\section{References}

1. Mandel L, Tharakan M. Treatment of unilateral masseteric hypertrophy with botulinum toxin: case report. J Oral Maxillofac Surg. 1999;57:1017-9.

2. Addante RR. Masseter muscle hypertrophy: report of case and literature review. J Oral Maxillofac Surg. 1994;52:1199-202.

3 . Ham JW. Masseter muscle reduction procedure with radiofrequency coagulation. J Oral Maxillofac Surg. 2009;67:457-63.

4. Smyth AG. Botulinum toxin treatment of bilateral masseteric hypertrophy. Br J Oral Maxillofac Surg. 1994;32:29-33.

5. Moore AP, Wood GD. The medical management of masseteric 
hypertrophy with botulinum toxin type $\mathrm{A}$. Br J Oral Maxillofac Surg. 1994;32:26-8.

6. Maestre-Ferrín L, Burguera JA, Peñarrocha-Diago M, Peñarrocha-Diago M. Oromandibular dystonia: a dental approach. Med Oral Patol Oral Cir Bucal. 2009;15:e25-7.

7. Martos Díaz P, Bances del Castillo R, Mancha de la Plata M, Naval Gías L, Martínez Nieto C, Lee GY, et al. Clinical results in the management of Frey's syndrome with injections of Botulinum toxin. Med Oral Patol Oral Cir Bucal. 2008;13:E248-52.

8. Fuster Torres MA, Berini Aytés L, Gay Escoda C. Salivary gland application of botulinum toxin for the treatment of sialorrhea. Med Oral Patol Oral Cir Bucal. 2007;12:E511-7.

9. Luna Ortiz K, Rascon Ortiz M, Sansón Riofrio JA, Villavicencio Valencia V, Mosqueda Taylor A. Control of Frey's syndrome in patients treated with botulinum toxin type A. Med Oral Patol Oral Cir Bucal. 2007;12:E79-84.

10. Kwon JS, Kim ST, Jeon YM, Choi JH. Effect of botulinum toxin type A injection into human masseter muscle on stimulated parotid saliva flow rate. Int J Oral Maxillofac Surg. 2009;38:316-20.

11. Al-Muharraqi MA, Fedorowicz Z, Al Bareeq J, Al Bareeq R, Nasser M. Botulinum toxin for masseter hypertrophy. Cochrane Database Syst Rev. 2009;1:CD007510.

12. Von Lindern JJ, Niederhagen B, Appel T, Bergé S, Reich RH. Type A botulinum toxin for the treatment of hypertrophy of the masseter and temporal muscles: an alternative treatment. Plast Reconstr Surg. 2001;107:327-32.

13. Harriman DG. The histochemistry of reactive masticatory muscle hypertrophy. Muscle Nerve. 1996;19:1447-56.

14. Serrat A, García-Cantera JM, Redondo LM. Isolated unilateral temporalis muscle hypertrophy. A case report. Int J Oral Maxillofac Surg. 1998;27:92-3.

15. Wilson PS, Brown AM. Unilateral temporalis muscle hypertrophy: case report. Int J Oral Maxillofac Surg. 1990;19:287-8.

16. Riefkohl R, Georgiade GS, Georgiade NG. Masseter muscle hypertrophy. Ann Plast Surg. 1984;12:528-32

17. To EW, Ahuja AT, Ho WS, King WW, Wong WK, Pang PC, et al. A prospective study of the effect of botulinum toxin A on masseteric muscle hypertrophy with ultrasonographic and electromyographic measurement. Br J Plast Surg. 2001;54:197-200.

18. Ahn KY, Kim ST. The change of maximum bite force after botulinum toxin type a injection for treating masseteric hypertrophy. Plast Reconstr Surg. 2007;120:1662-6. 